\title{
Neonicotinoid insecticides are potential substrates of the multixenobiotic resistance (MXR) mechanism in the non-target invertebrate, Dreissena sp.
}

\author{
Ágnes Vehovszky ${ }^{\mathrm{a}}$, Anna Farkas ${ }^{\mathrm{a}}$, Vivien Csikós ${ }^{\mathrm{a} 1}$, András Székács ${ }^{\mathrm{b}}$, Mária Mörtl ${ }^{\mathrm{b}}$, János Győri ${ }^{\mathrm{a}}$ \\ ${ }^{a}$ MTA Centre for Ecological Research, Balaton Limnological Institute, Tihany, Hungary, ${ }^{\mathrm{b}}$ Agro- \\ Environmental Research Institute, National Agricultural Research and Innovation Centre, Budapest, \\ Hungary
}

\begin{abstract}
Mussels are among the most frequently used invertebrate animals in aquatic toxicology to detect toxic exposure in the environment. The presence and activity of a cellular defence system, the multixenobiotic resistance (MXR) mechanism, was also established in these organisms.

In isolated gill tissues of dreissenid mussels (D. bugensis) the MXR activity was assayed after treatment by commercially available insecticides (formulated products) which contain neonicotinoids as their active ingredients: Actara (thiamethoxam), Apacs (clothianidin), Calypso (thiacloprid) and Kohinor (imidacloprid), respectively. While applying the accumulation assay method, $0.5 \mu \mathrm{M}$ rhodamine B was used as model substrate and $20 \mu \mathrm{M}$ verapamil as model inhibitor of the MXR mechanism.

In acute (in vitro) experiments when isolated gills were co-incubated in graded concentrations of insecticides and rhodamine B simultaneously, Calypso and Kohinor treatment resulted increasing rhodamine accumulation. Chemical analysis of gills in vitro incubated in insecticides demonstrated higher tissue concentrations of thiamethoxam, clothianidin and thiacloprid in the presence of verapamil suggesting that the active ingredients of Actara, Apacs and Calypso are potential substrates of the MXR mediated cellular efflux. In contrast, verapamil did significantly alter the accumulated imidacloprid concentrations in gills, suggesting that the active component of Kohinor is not transported by the MXR mechanism.

Chronic (in vivo) exposures of the intact animals in lower, $1,10 \mathrm{mg} / \mathrm{L}$ concentration of neonicotinoid products, resulted in a decreased level of both rhodamine accumulation and verapamil inhibition by the $12^{\text {th }}-14^{\text {th }}$ days of treatment. These results suggest an enhancement of MXR activity (chemostimulation), building up gradually in the animals exposed to Actara, Apacs and Kohinor, respectively.

Neonicotinoid-type insecticides are generally considered as selective neurotoxins for insects, targeting the nicotinic type acetylcholine receptors (nAChRs) in their central nervous system. Our present results provide the first evidences that neonicotinoid insecticides are also able to alter the transmembrane transport mechanisms related to the MXR system.
\end{abstract}

\section{Keywords}

Neonicotinoids, multixenobiotic resistance, QuEChERS analysis, chemostimulation, Dreissena

\section{Introduction}

During normal agrochemical activity or accidental leakage, neonicotinoid insecticides may appear and potentially accumulate in surface waters and soil (Schaafsma et al., 2015; Anderson et al., 2015; Morrisey et al., 2015). These types of insecticide are generally regarded as highly selective

\footnotetext{
${ }^{1}$ present address: Eötvös Loránd University Budapest, Hungary
} 
neurotoxins for insects, inhibiting the nicotinic-type acetylcholine receptors (nAChRs) in the central nervous system (Tomizawa and Casida, 2005). Recent literature data also suggest, that neonicotinoids affect probably far more taxa and exert much wider ecological effects than was expected since this third generation of insecticides was introduced (Morrissey et al., 2015; SimonDelso et al., 2015). Accumulating data demonstrate that neonicotinoid effects are not confined in the CNS, but potentially act more systematically and also induce intracellular alterations, both in vertebrates and invertebrates, (Nwozo et al., 2015; Brandt et al., 2016; Kataria et al., 2016; Sheets et al., 2016; Kudelska et al., 2017; Tavares, et al., 2017).

Aquatic animals, particularly benthic and sessile invertebrates, are mostly exposed to environmental pollutants, which are easily transported into the body by diffusion through the skin and gills or consumed during feeding. To prevent accumulation of toxic xenobiotics, both natural and anthropogenic, the multixenobiotic resistance, MXR mechanism (also called multixenobiotic defence, MXD) provides a cellular defence, driving a transmembrane efflux of the intracellularly accumulated toxic molecules and their harmful conjugates back into the extracellular space (Bard 2000; Epel et al., 2008). The MXR system characterizes all living cells, their transport proteins can be identified across all animal taxa and in other organisms, including bacteria, plants and fungi (Buss and Callaghan, 2008). The role of an analogous mechanism called MDR (multidrug resistance) was established nearly 50 years ago and found responsible for decreasing sensitivity of bacteria or tumor cells to pharmacological treatments (Biedler et al., 1970; Dano et al., 1973). All these cellular defences (MXR, MDR) share common features, including their membrane transporters, members of the membrane bound superfamily of ATP binding cassette (ABC) proteins (Litman et al., 2001; Jeong et al., 2017). Both MDR and MXR systems are characterized by a rather broad substrate and inhibitor specificity (Bain et al., 1997; Litman et al., 2001; Buss and Callaghan, 2008). Constant exposure of toxic molecules as chemostimulators by enhancing MXR activity, and numerous other chemicals regarded as chemosensitizers, inhibit this defence mechanism (Choi et al., 2005; Smital et al., 1998, 2003, 2004; Epel et al., 2008).

Molluscs, and particularly mussels are among the most frequently used invertebrate animals in aquatic toxicology, as their sessile habitat and filtration activity make them suitable indicators to detect and monitor toxic chemicals in the environment and also to study the physiological and biochemical alterations evoked by harmful exposure (Salánki et al., 2003; Rittschof et al., 2005; Borcherding, 2006; Falfushynska, et al., 2010). The presence and activity of the MXR mechanism were also established in mussels, including Dreissena sp. (Cornwall et al., 1995; Smital et al., 2000; Pain and Parant 2003; Rioult et al., 2014). Alteration (activation or inhibition) of this cellular defence system may also serve as a biological indicator of environmental pollution (Pain and Parant 2007; Contardo-Jara and Wiegand 2008; Luckenbach and Epel, 2008; Ács et al., 2015; Jeong et al., 2017).

Enhanced activation of the MXR mechanism is usually due to longer lasting (chronic) effects, resulting in increased gene expression of two (P-gp, MRP) subclasses of ABC proteins (Faria et al., 2011; Navarro et al., 2011; Navarro et al., 2012; Chatel et al., 2015), although transcription (translation) and transporter activity level cannot be always directly correlated (Tutundjian and Minier, 2007; Jeong et al., 2017). We cannot exclude, that activity of the MXR system in mussels might contribute in their rather robust resistance to neonicotinoids compared with insects on the rather wide sensitivity scale of aquatic invertebrates (Rico and Van Den Brink, 2015).

To assess the activity of the MXR system in the presence of neonicotinoid insecticides, we used dreissenid mussels as aquatic, non-target model animals. Both Dreissena bugensis and $D$. polymorpha species form abundant populations in Lake Balaton (Hungary) although recently $D$. bugensis seem to be most dominant in the region. Balogh et al. (2018) followed the invasion of quagga mussels in lake Balaton between 2009 and 2013 and found $80 \%$ the relative abundance of 
D. bugensis in 2012, reaching as high as $98 \%$ by the year 2013). Moreover, recent toxicological assays on the specimens collected in the same locations (T1, T2 in front of the BLI building, Tihany peninsula; Balaton area, see Fig 1, Balogh et al, 2018), did not show statistically significant variability in a number of intracellular markers (Farkas et al., 2017).

Whole animal assays are often preferred as repeatable, non-invasive methods for testing MXR mechanism in mussels (Smital and Kurelec, 1997; Pain and Parant, 2007; Contardo-Jara and Wiegand, 2008; Ács et al., 2015). However, we cannot rule out that biologically active xenobiotics may also affect other, neuronal and physiological processes, modulating the behavioural activity of the animal. In mussels particularly, filtering (involved in both respiration and feeding) may also be altered by toxicological treatment (Kontreczky et al., 1997; Ayad et al., 2011; Potet et al., 2016), therefore, the final dose cannot be determined exactly by whole animal testing (Pain and Parant, 2003).

In our present study, isolated gills of the experimental animals were used for MXR assays both after in vitro and in vivo exposures. Isolated gill tissue survives in water for several hours, allowing direct access of chemicals to the tissue samples, and also provides a reasonably simple object for further (analytical, cellular, molecular) studies of drug-evoked changes, including the MXR mechanism (Cornwall et al., 1995; Eufemia and Epel, 2000; Luckenbach and Epel, 2008; Navarro et al., 2012).

\section{Materials and methods}

\subsection{Animals}

Adult (18-22 mm) animals (D. bugensis specimens) were collected locally (Lake Balaton, Hungary), and maintained in glass aquaria (approximately 1000 individuals/aquarium) with a capacity of $120 \mathrm{~L}$ supplied with a flow of well-aerated unfiltered water $\left(\mathrm{T}=18 \pm 2{ }^{\circ} \mathrm{C}\right)$ directly taken from the Lake (flow rate approximately $700 \mathrm{~mL} / \mathrm{min}$ ). A week before testing about 250 animals were separated in $15 \mathrm{~L}$ containers with aerated water, providing the pool for experimental animals. During chronic (in vivo) treatments the replacement insecticide solutions (see 2.3.3.) were made from fresh Balaton water, also containing food supply for experimental animals.

\subsection{Chemicals}

We used the formulated products of insecticides commercially available in Hungary, which contain neonicotinoids as their active ingredients (names in brackets): Actara (thiamethoxam) from Syngenta, Apacs (clothianidin) from Arysta Life Science, Calypso (thiacloprid) from Bayer and Kohinor (imidacloprid) from Makteshim Agan. The accurate concentrations of the active ingredients in solutions of each neonicotinoid product were confirmed by HPLC-UV chromatography.

The analytical standards of Pestanal grade were purchased from Merck (Darmstadt, Germany), while the other chemicals: rhodamine B, verapamil hydrochloride and the chemicals for the Bradford assay (Bradford 1976) were purchased from SIGMA.

\subsection{Treatments}

2.3.1. The acute (direct) effects of the insecticides were studied on the isolated gills of nontreated animals, by simultaneous incubation of the samples in $0.5 \mu \mathrm{M}$ rhodamine $\mathrm{B}$ and the formulated products (Actara, Apacs, Calypso, Kohinor, respectively) dissolved in filtered Balaton water. To compare their effects we applied equimolar, $(1,10,30,50,250 \mu \mathrm{M})$ concentrations of neonicotinoid components (thiamethoxam in Actara, clothianidin in Apacs, etc.), corresponding up to a maximum of $125-320 \mathrm{mg} / \mathrm{L}$ formulation, depending on the chemical composition of the product. 
2.3.2. For chemical analysis the isolated gills were incubated in aqueous solutions of insecticides (without rhodamine B) and paired samples were processed by the standardized loading assay protocol with and without verapamil (see below, 2.4.) before analytical measurements (see 2.5. in Materials and Methods).

2.3.3. The chronic effects of the insecticides were also tested in vivo, by placing the intact animals in plastic containers filled with solutions of formulated insecticides. For each formulation the tested $(1 \mathrm{mg} / \mathrm{L}$ and $10 \mathrm{mg} / \mathrm{L})$ concentrations corresponded to the NOEL (No Effect Level) threshold for filtration rate and lethality of intact Dreissena specimens within the extended exposure regime. After 24 hours and then on the $6^{\text {th }}, 12^{\text {th }}, 14^{\text {th }} 25^{\text {th, }}$ and $32^{\text {nd }}$ days of exposure, the animals were dissected to isolate their gills for MXR assays. Insecticides $(1,10 \mathrm{mg} / \mathrm{L})$, were diluted in fresh Balaton water and replaced in the containers every 48 hours during the exposition period.

\subsection{MXR assay}

On isolated gill samples we applied the already established ,accumulation” method of MXR assay where rhodamine B served as a model P-gp substrate and verapamil was used as its inhibitor (Cornwall et al., 1995; Faria et al., 2011; Smital and Kurelec 1997; Smital et al., 2003, etc.). During the incubation (loading) period, rhodamine is taken up by a gradient-controlled uptake process intracellularly, while the MXR mechanism mediated by specific (ABC) membrane transport proteins drives an active efflux of the accumulated rhodamine against the concentration gradient (Fig. 1A1). In the presence of verapamil the rhodamine accumulation is enhanced, due to partial block of the MXR controlled efflux (Fig. 1A2). To assess the activity of MXR mechanism the accumulated rhodamine levels of tissues incubated in rhodamine are compared with samples co-incubated in rhodamine with verapamil (Fig 1B).

During our experiments a pair of gills was freshly dissected from each of the animals then incubated in filtered water containing either $0.5 \mu \mathrm{M}$ rhodamine $\mathrm{B}$, a mixture of $0.5 \mu \mathrm{M}$ rhodamine $\mathrm{B}$ and $20 \mu \mathrm{M}$ verapamil for 60 minutes (loading), followed by a short (10 min) washing in $40 \mu \mathrm{M}$ verapamil containing water, which allowed the removal of excess dye from the surface of tissues but inhibited the active (MXR controlled) efflux. Before the chemical analysis, the isolated gills were similarly incubated for 60 min either in aqueous solutions of insecticide or in a medium containing the same concentrations of insecticide and $20 \mu \mathrm{M}$ verapamil.

To quantify the level of accumulated rhodamine in different samples, we applied the uptake quotient $\%$, calculated in percentage values of fluorescence of the treated samples divided by the values of control samples (Kurth et al., 2017). MXR activity was also assessed by the inhibitory potential of verapamil, based on the differences of rhodamine accumulation data with and without verapamil. The ratio $(\mathrm{R})$ of rhodamine levels in control vs. verapamil treatment quantifies these data (Smital et al., 2000). Higher MXR activity corresponds with lower $\mathrm{R}$ value $\left(\operatorname{Rod}<<\operatorname{Rod}_{\mathrm{ver}}\right)$ while low MXR activity is suggested by higher $R$ value, up to $R=1$.

\subsection{Sample preparation}

After finishing the incubation/treatment protocols the gill tissue samples were individually placed in $2 \mathrm{~mL}$ Eppendorf tubes with $0.5 \mathrm{~mL}$ distilled water and frozen for 2 hours before further processing. The samples were then homogenized in a tissue lyzer (Tyssuelyzer LT, Qiagen) and centrifuged at $8000 \mathrm{~g}$ for $10 \mathrm{~min}$ at $4^{\circ} \mathrm{C}$ (Biofuge Fresco, HERAUS ). The fluorescence of the supernatant $(250 \mu \mathrm{L})$ was finally measured at $\lambda_{\mathrm{ex}}=535 \mathrm{~nm}$ and $\lambda_{\mathrm{em}}=590 \mathrm{~nm}$ (Victor 3 plate-reader, Perkin Elmer) to determine the amount of accumulated rhodamine B in the tissue samples. The protein concentration of the tissue homogenates was also determined in parallel samples applying the Bradford assay (Bradford 1976), and the final values of rhodamine accumulation data were normalized to the total protein content of the samples (fluorescence units per mg tissue protein). 


\subsection{Chemical analysis}

For analytical determination of active ingredients we applied QuEChERS methodology (Anastassiades et al., 2003; González-Curbelo et al., 2015) originally developed to extract the pesticide active ingredients from food samples, and also used for the extraction of neonicotinoid insecticides from soil samples (Mörtl et al., 2016).

In our procedure $300 \mu \mathrm{L}$ phosphate buffer $(\mathrm{pH}$ 7.2) and $1 \mathrm{~mL}$ of acetonitrile were added to the aliquot of the frozen homogenized tissue, then stirred by vortex for $30 \mathrm{~s}$ and sonicated for 10 min. Salting-out step involved the addition of $9 \mathrm{mg} \mathrm{MgSO} 4,2.25 \mathrm{mg} \mathrm{NaCl}$ and $4 \mathrm{mg}$ citrate buffer, followed by homogenization (vortex and ultrasound agitation for $5 \mathrm{~min}$ ). After centrifugation (10 $\left.\min , 3000 \mathrm{rpm}, 4^{\circ} \mathrm{C}\right), 900 \mu \mathrm{L}$ of supernatant was subjected to clean-up by using $0.41-0.41 \mathrm{mg}$ of primary secondary amine (PSA) and C18 dispersive phases. After stirring and centrifugation of the suspension, $800 \mu \mathrm{l}$ of supernatant was transferred into a vial and the solvent evaporated to dryness under a nitrogen stream. The residue was dissolved in eluent $(65: 35=\mathrm{A}$ : $\mathrm{B}$ eluents, $\mathrm{A}=90 \%$ water: $10 \% \mathrm{MeOH}, \mathrm{B}=\mathrm{MeOH})$, filtered through a $0.45 \mu \mathrm{m}$ polytetrafluoroethylene syringe filter (Labex Ltd. Budapest, Hungary) prior to analysis. We used our slightly modified isocratic method (Mörtl et al., 2016) for determination of neonicotinoids. The target components were separated on a C18 column purchased from MZ Analysentechnik (PerfectSil 100 ODS-3, $150 \mathrm{~mm} \times 4.6 \mathrm{~mm}$ i.d., 5 $\mu \mathrm{m})$ at $40^{\circ} \mathrm{C}$. UV detector signals were recorded at $\lambda=269 \mathrm{~nm}$ and $\lambda=252 \mathrm{~nm}$. The external calibration was performed with seven standard solutions in the range between $0.100 \mathrm{mg} / \mathrm{L}$ and 10 $\mathrm{mg} / \mathrm{L}$. The eluent flow rate was $1.0 \mathrm{~mL} / \mathrm{min}$ with isocratic elution for $8 \mathrm{~min}(65: 35=\mathrm{A}$ : $\mathrm{B}$ eluents, $\mathrm{A}$ $=90 \%$ water : $10 \% \mathrm{MeOH}, \mathrm{B}=\mathrm{MeOH}$ ). The Limit of detection (LOD) determined with standard solutions were at $0.010 \mathrm{mg} / \mathrm{L}$ for thiamethoxam, thiacloprid and below $0.010 \mathrm{mg} / \mathrm{L}$ for clothianidin and imidacloprid. The retention times were 3.22, 4.21, 4.55 and $7.14 \mathrm{~min}$, the ratios of signal intensities (peak areas) recorded at $269 \mathrm{~nm}$ and at $252 \mathrm{~nm}$ were $0.59,1.96,1.23$ and 0.39 for thiamethoxam, imidacloprid, clothianidin and thiacloprid, respectively. The protein concentration of the tissue homogenates was also determined in parallel samples applying the Bradford assay (Bradford, 1976). The concentrations of neonicotinoids were finally expressed as mass unit of neonicotinoid (active ingredient) per that of tissue protein.

\subsection{Data analysis}

All data were presented as mean values with standard deviations calculated on six replicates. The significance of differences in rhodamine-B accumulation (fluorescence data) and neonicotinoid concentrations in the absence or presence of the model inhibitor verapamil, was assessed by Student's $t$-tests $(p<0.05)$. The significance of differences in rhodamine-B uptake quotients were tested by one-way analysis of variance (ANOVA) followed by Tukey's post hoc test $(p<0.05)$. When necessary, the data were transformed to ensure equal variances. Mean differences were considered significant at $p<0.05$. Data were statistically analysed and plotted with the OriginPro software package (OriginLab Corporation, USA).

\section{Results}

\subsection{Acute (in vitro) exposures by insecticides}

In isolated gills simultaneously incubated in $0.5 \mu \mathrm{M}$ rhodamine B solution and graded concentrations of formulated neonicotinoid insecticides (equimolar, 1-250 $\mu \mathrm{M}$ of active ingredients), rhodamine accumulation data showed diverse effects of treatments (Fig. 2). Actara and Apacs (up to $290 \mathrm{mg} / \mathrm{L}$ and $125 \mathrm{mg} / \mathrm{L}$ product concentrations, respectively) did not evoke significant enhancement of rhodamine content (Fig 2A,C). Identical treatment with Kohinor and Calypso applied in the same 
range of concentrations (a maximum of $320 \mathrm{mg} / \mathrm{L}$ and $125 \mathrm{mg} / \mathrm{L}$, respectively) resulted in (up to 350 $\%$ ) accumulation increase of rhodamine B (Fig. 2B,D).

Isolated gill tissues were also incubated in selected doses of insecticide solutions without rhodamine to determine the accumulated neonicotinoid ingredients in the tissues treated by formulations (Fig. 3). Analytical measurements showed about the same magnitude of neonicotinoid concentrations in tissue homogenates after Actara, Apacs and Kohinor treatment (thiamethoxam, clothianidin and imidacloprid, respectively) as seen on Fig. 3A,B,C. The gill samples incubated in Calypso by the same protocol, however, showed about a magnitude higher level of thiacloprid (Fig 3D). Moreover, co-incubation of tissues in Actara, Apacs and Calypso with verapamil resulted in significantly higher levels of their neonicotinoid components (Fig A,C,D), while verapamil in Kohinor treated samples did not result in increased accumulation of imidacloprid (Fig. 3B). While comparing the insecticide products as MXR substrates by the assay protocol ( $\mathrm{R}$ ratio, meaning the accumulation of the active ingredients with and without verapamil) a ranking order could also be established: Calypso $>$ Apacs $>$ Actara $(R=0.32 \pm 0.11,0.51 \pm 0.10,0.62 \pm 0.23$; mean $\pm S D ; n=6)$.

\subsection{Chronic tretaments, in vivo exposures}

MXR activities in gill tissues were also assayed after the intact animals were exposed in lower $(1,10 \mathrm{mg} / \mathrm{L})$ concentrations of formulated insecticides. Data from in vivo chronic treatments showed similar trends, decreasing rhodamine accumulation during the longer time exposure, although quantified data also revealed differences in the effects of the insecticides applied. Exposures of the intact animals in Apacs and Kohinor $(10 \mathrm{mg} / \mathrm{L})$ resulted in significantly lower levels of rhodamine accumulation (seen as decreased uptake values on Fig. 4A2,B2), but the decreased uptake level of Calypso treated samples did not show significance (Fig. 4C2). Although the rhodamine accumulation in verapamil treated tissues also slightly decreased, the differences in accumulation data between the sample groups incubated in rhodamine alone (Fig 4, A1,B1,C1; Rod) and in verapamil (Fig. 4A1,B1,C1; Rod+Ver) were actually enhanced. Increasing inhibitory effects of verapamil is well demonstrated by comparing the $\mathrm{R}$ ratios, which were significantly lower in samples treated in 10mg/L Apacs for 14 days (Fig. 4A2). Longer (up to $32^{\text {nd }}$ days) exposure in Kohinor however, also demonstrated a time dependent decrease of both the uptake quotient (Fig. 5A) and the R2/R1 ratio, comparing treated samples with the same day control (Fig. 5A, right axis). While comparing the efficacy of the insecticides we applied, quantitative data revealed that the Apacs-treated samples displayed the stronger (significant) decrease of both accumulation and verapamil inhibition, while Calypso treatment resulted much less, not significant alterations of the same parameters (Fig. 5B).

\section{Discussion}

\subsection{Experimental results}

Summarized in vitro results revealed rather diverse effects of different insecticide products while testing (in vitro) on isolated gill tissues. Actara and Apacs did not alter the MXR activity (assessed by rhodamine accumulation data), but chemical analysis of verapamil treated samples suggested, that their active ingredients, thiamethoxam and clothianidin, respectively, are very likely substrates of the MXR mechanism.

Applying Kohinor and Calypso resulted in an accumulation increase of rhodamine B in isolated gill tissues, similarly to the dose-dependent enhancement of rhodamine concentration in the presence of the MXR inhibitor verapamil (Cornwall et al., 1995). Very recently Wathsala, et al (2018) suggested reduced MXR activity by higher rhodamine accumulation following an identical co-incubation protocol of styrene on treated mussel embryos. 
These results, however, provide no direct evidence against that the active component of Kohinor, imidacloprid is transported intracellularly but the lack of verapamil effect on imidacloprid accumulation indicates, that this neonicotinoid is not transported extracellularly by the MXR mechanism. Chemosensitizers (MXR, MDR inhibitors), are not necessarily substrates of the efflux system, as they may interact either on the substrate binding site or the regulatory part of the transporter (P-gp, MRP) molecules (reviewed by Epel et al., 2008; Buss and Callaghan, 2008; Kurth et al., 2017).

Calypso, however, provided some contradictory results, while comparing in vitro rhodamine accumulation assays with the analytical measurements. Calypso treated tissues showed increasing accumulation of rhodamine suggesting competitive inhibition of the transmembrane efflux, but the higher concentration values of thiacloprid in the presence of verapamil clearly indicated the activity of the MXR system. Additionally, although all insecticid products were applied in equimolar concentrations of their active components (thiamethoxam in Actara, clothianidin in Apacs, etc), the thiacloprid levels in Calypso incubated tissues were measured in magnitude higher concentrations compared to the neonicotinoid levels of tissues treated by Actara, Apacs or Kohinor.

Based on literature data we may also consider the role of formulating chemicals, in Calypso particularly, the (10\%) glycerol content according to the safety data sheet (MSDS Canada). Glycerol is known to facilitate membrane permeability of lipids and fluorescent dyes without affecting their viability (Doan and Obbard, 2011; Natunen et al., 2015; Aleman-Nava et al., 2016). We cannot exclude a non-selective permeability enhancement resulted by the glycerol content in Calypso leading to higher accumulation of both rhodamine B and the active component, thiacloprid. Easier penetration through the gill tissue membranes may also increase the efficacy of the energy demanding MXR efflux mechanism, suggested by the lowest $R$ value of thiacloprid accumulation compared with other neonicotinoids the active components of Actara and Apacs (thiamethoxam, clothianidin, respectively).

During chronic experiments (in vivo exposures) of intact animals at lower $(1,10 \mathrm{mg} / \mathrm{L})$ insecticide concentrations (which did not significantly affect the physiology of intact animals, neither the rhodamine uptake by in vitro exposures) Actara and Apacs proved to be the most effective insecticides to decrease rhodamine accumulation and increase verapamil effect, all suggesting enhanced MXR mechanisms after longer exposure. Kohinor had similar effects, but required a longer time to build up significant changes. Calypso, although by in vitro results its active component apparently behaves as a substrate of the MXR system, during similarly long exposure duration, only evoked slight, but not significant changes in the parameters measured (uptake quotient and $\mathrm{R}$ value).

Increased MXR activity is usually due to enhanced gene expression/translation of the transmembrane (P-gp or MRP) proteins, but initially it requires intracellular activation of the PXR receptors, acting as a transcription factor (reviewed by Jeong et al., 2017). Based on our summarized data, we assume that the neonicotinoids (the active ingredients of the products) of the insecticides tested are initially taken up intracellularly, and stimulate the PXR receptors responsible for enhanced gene expression for MXR activation.

\section{2. $M X R$ and neonicotinoids}

Although the broad substrate specificity of both the cellular uptake and the $\mathrm{ABC}$ protein controlled efflux mechanism is well established (Bain et al., 1997; Dobson et al., 2009; Kell, 2015; Buss and Callaghan, 2008), only a very few experimental data are available, suggesting interactions of neonicotinoids with these transmembrane systems. Dose-dependent, saturable uptake and ATPdependent efflux of acetamiprid and imidacloprid has been demonstrated using human tissues (Brunet et al., 2004, 2008). Selective accumulation of acetamiprid is also published both in 
invertebrate (Gammarus, Lymnaea) and vertebrate tissues (Nyman et al., 2014; Terayama et al., 2016). There is even less indirect data in the literature to suggest that neonicotinoids are also substrates of the MXR (MDR) mechanisms. MXR inhibiting compounds, including verapamil, orally administered to honey bees resulted in higher mortality to imidacloprid-, acetamiprid-, or thiacloprid-containing neonicotinoid insecticides (Hawthorne 2011; Guseman et al., 2016).

To our best knowledge we provide the first results regarding accumulation and verapamil inhibition data in tissues treated with neonicotinoid insecticides. As a result, we conclude that some neonicotinoid ingredients act as MXR substrates (thiamethoxam, clothianidin, thiacloprid), while formulating product may directly inhibit the MXR system as chemisensitizers (Kohinor) or enhance MXR activity during longer exposures as chemostimulators (Actara, apacs, Kohinor).

\subsection{Environmental significance}

While testing neonicotinoid insecticides we used commercially available formulations where the active ingredients are present in combination with other, additional components (solvents, emulsifiers, etc). To establish general toxicity and cellular/molecular mechanisms behind these effects, laboratory assays mostly apply the active ingredients, but agrochemicals, including neonicotinoids in the field, appear as formulations, complex mixtures of chemicals. Comparative studies suggest that formulated products often evoke stronger effects (higher toxicity) compared to pure ingredients (Margues et al., 2012; Neves et al., 2015).

The complex effects of the insecticides tested in our laboratory experiments may also result in different environmental consequences when applied as agrochemicals. Higher concentration ranges usually correspond with the stock solutions of insecticides by manufacturer's recommendation or could appear during accidental leakage or misuse of the products. As our results suggest, in this situation neonicotinoids may act as chemosensitizers, making the organism more sensitive to other xenobiotics that appear simultaneously in the same environment (Hawthorne et al., 2011; Anselmo et al., 2012; Guseman et al., 2016). These synergistic effects of combinations of pesticides and other harmful chemicals may result in unfavourable effects (impaired physiological functions, mortality) at lower concentrations than assessed by laboratory data (Sgolastra et al., 2017).

Low concentration, but longer time exposure of insecticides, when MXR activity is enhanced, may counteract with (or partially compensate) the harmful effects of other environmental pollutants. However, they also potentially contribute to the development of a higher resistance against other agrochemicals (herbicides, fungicides, etc) requiring higher application dose and posing higher environmental risk (Bard, 2000; Buss and Callagham, 2008).

Earlier electrophysiological results (Vehovszky et al., 2015) provided evidences that similarly as in the insects, neonicotinoids also target the nicotinic type acetylcholine receptors (nAChRs) in the central nervous system of the pond snail, Lymnaea stagnalis. Our recent results show additional data that neonicotinoid insecticides may also alter the transmembrane transport mechanisms of the cellular defence, the multixenobiotic (MXR) system in molluscs.

\section{Acknowledgement}

This project was supported by the Hungarian Scientific Research Fund OTKA K-112712. The authors express their special thanks to Professor Robert J. Walker (University of Southampton, UK) for his helpful comments on the manuscript. Thank is due to Zsuzsa Fekete, Judit Néma and Sára Surguta for their contributions in sample preparations, moreover, to Judit Juracsek and Csilla Magor for their assistance in the analytical measurements. 


\section{References}

Acs, A., Imre, K., Kiss, G., Csaba, J., Gyori, J., Vehovszky, A., Farkas, A., 2015. Evaluation of multixenobiotic resistance in dreissenid mussels as a screening tool for toxicity in freshwater sediments. Arch. Env. Cont. Toxicol. 68, 707-717.

Aleman-Nava, G.S., Cuellar-Bermudez, S.P., Cuaresma, M., Bosma, R., Muylaert, K., Ritmann, B.E., Parra, R., 2016. How to use Nile Red, a selective fluorescent stain for microalgal neutral lipids. J. Miscrobiol. Meth. 128, 74-79.

Anastassiades, M., Lehotay, S.J., Stajnbaher, D., Schenck, F.J., 2003. Fast and easy multiresidue method employing acetonitrile extraction/partitioning and "dispersive solid-phase extraction" for the determination of pesticide residues in produce. J. AOAC International 86, 412-431.

Anderson, J.C., Dubetz, C., Palace, V.P., 2015. Neonicotinoids in the Canadian aquatic environment: a literature review on current use products with a focus on fate, exposure, and biological effects. Sci. Total. Env. 505, 409-422.

Anselmo, H.M., van den Berg, J.H., Rietjens, I.M., Murk, A.J., 2012. Inhibition of cellular efflux pumps involved in multi xenobiotic resistance (MXR) in echinoid larvae as a possible mode of action for increased ecotoxicological risk of mixtures. Ecotoxicology 21, 2276-2287.

Ayad, M.A., Fdil, M.A., Mouabad, A., 2011. Effects of Cypermethrin (pyrethroid insecticide) on the valve activity behavior, byssal thread formation, and survival in air of the marine mussel Mytilus galloprovincialis. Arch. Env. Cont. Toxicol. 60, 462-470.

Bain, L.J., McLachlan, J.B., LeBlanc, G.A., 1997. Structure-activity relationships for xenobiotic transport substrates and inhibitory ligands of P-glycoprotein. Environ. Health. Persp. 105, 812-818.

Balogh, C., Vlacilova, A., G-Toth, L., Serfozo, Z., 2018. Dreissenid colonization during the initial invasion of the quagga mussel in the largest Central European shallow lake, Lake Balaton, Hungary. J. Great Lakes Res. 44, 114-125.

Bard, S.M., 2000. Multixenobiotic resistance as a cellular defense mechanism in aquatic organisms. Aquat. Toxicol. 48, 357-389.

Biedler, J.L., Riehm, H., 1970. Cellular resistance to actinomycin D in Chinese hamster cells in vitro: cross-resistance, radioautographic, and cytogenetic studies. Cancer Res. 30, 1174-1184.

Borcherding, J., 2006. Ten years of practical experience with the Dreissena-Monitor, a biological early warning system for continuous water quality monitoring. Hydrobiologia 556, 417-426.

Bradford, M.M., 1976. A rapid and sensitive method for the quantitation of microgram quantities of protein utilizing the principle of protein-dye binding. Anal. Biochem. 72, 248-254.

Brandt, A., Gorenflo, A., Siede, R., Meixner, M., Buchler, R., 2016. The neonicotinoids thiacloprid, imidacloprid, and clothianidin affect the immunocompetence of honey bees (Apis mellifera L.). J. Insect Physiol. 86, 40-47.

Brunet, J.L., Maresca, M., Fantini, J., Belzunces, L.P., 2004. Human intestinal absorption of imidacloprid with Caco-2 cells as enterocyte model. Toxicol. Appl. Pharmacol. 194, 1-9.

Brunet, J.L., Maresca, M., Fantini, J., Belzunces, L.P., 2008. Intestinal absorption of the acetamiprid neonicotinoid by Caco-2 cells: transepithelial transport, cellular uptake and efflux. J. Env. Sci. Health B, 43, 261-270.

Buss, D.S., Callaghan, A., 2008. Interaction of pesticides with p-glycoprotein and other ABC proteins: A survey of the possible importance to insecticide, herbicide and fungicide resistance. Pestic. Biochem. Physiol. 90, 141-153.

Chatel, A., Faucet-Marquis, V., Gourlay-France, C., Pfohl-Leszkowicz, A., Vincent-Hubert, F., 2015. Genotoxicity and activation of cellular defenses in transplanted zebra mussels Dreissena polymorpha along the Seine river. Ecotoxicol. Environ. Safety 114, 241-249.

Choi, C.H., 2005. ABC transporters as multidrug resistance mechanisms and the development of chemosensitizers for their reversal. Cancer Cell. Int. 5, 30.

Contardo-Jara, V., Wiegand, C., 2008. Molecular biomarkers of Dreissena polymorpha for evaluation of renaturation success of a formerly sewage polluted stream. Environ. Poll. 155, 182-189. 
Cornwall, R., Toomey, B.H., Bard, S., Bacon, C., Jarman, W.M., Epel, D., 1995. Characterization of Multixenobiotic Multidrug Transport in the Gills of the Mussel Mytilus-Californianus and Identification of Environmental Substrates. Aquatic Toxicol. 31, 277-296.

Dano, K., 1973. Active outward transport of daunomycin in resistant Ehrlich ascites tumor cells. Biochim. Biophys. Acta $323,466-483$.

Doan, T.T.Y., Obbard, J.P., 2011. Improved Nile Red staining of Nannochloropsis sp. J. Appl. Phycol. 23, 895-901.

Dobson, P.D., Lanthaler, K., Oliver, S.G., Kell, D.B., 2009. Implications of the dominant role of transporters in drug uptake by cells. Curr. Top. Med. Chem. 9, 163-181.

Epel, D., Luckenbach, T., Stevenson, C.N., Macmanus-Spencer, L.A., Hamdoun, A., Smital, T., 2008. Efflux transporters: newly appreciated roles in protection against pollutants. Env. Sci. Technol. 42, 3914-3920.

Eufemia NA, Epel D (2000) Induction of the multixenobiotic defense mechanism (MXR), P-glycoprotein, in the mussel Mytilus californianus as a general cellular response to environmental stresses. Aquat Toxicol 49:89-100

Falfushynska, H.I., Gnatyshyna, L.L., Farkas, A., Vehovszky, A., Gyori, J., Stoliar, O.B., 2010. Vulnerability of biomarkers in the indigenous mollusk Anodonta cygnea to spontaneous pollution in a transition country. Chemosphere $81,1342-1351$.

Faria, M., Navarro, A., Luckenbach, T., Pina, B., Barata, C., 2011. Characterization of the multixenobiotic resistance (MXR) mechanism in embryos and larvae of the zebra mussel (Dreissena polymorpha) and studies on its role in tolerance to single and mixture combinations of toxicants. Aquatic Toxicol. 101, 78-87.

Farkas, A., Acs, A., Vehovszky, A., Falfusynska, H., Stoliar, O., Specziar, A., Gyori, J., 2017. Interspecies comparison of selected pollution biomarkers in dreissenid spp. inhabiting pristine and moderately polluted sites. Sci. Total. Environ. 599-600, 760-770.

Fernandez-Sanjuan, M., Faria, M., Lacorte, S., Barata, C., 2013. Bioaccumulation and effects of perfluorinated compounds (PFCs) in zebra mussels (Dreissena polymorpha). Environ. Sci. Poll. Res. 20, 2661-2669.

González-Curbelo, M.Á., Socas-Rodríguez, B., Herrera-Herrera, A.V., González-Sálamo, J., Hernández-Borges, J., Rodríguez-Delgado, M.Á. 2015. Evolution and applications of the QuEChERS method. Trends in Anal. Chem. 71, 169185.

Guseman, A.J., Miller, K., Kunkle, G., Dively, G.P., Pettis, J.S., Evans, J.D., vanEngelsdorp, D., Hawthorne, D.J., 2016. Multi-Drug Resistance Transporters and a Mechanism-Based Strategy for Assessing Risks of Pesticide Combinations to Honey Bees. PloS one 11, e0148242.

Hawthorne, D.J., Dively, G.P., 2011. Killing them with kindness? In-hive medications may inhibit xenobiotic efflux transporters and endanger honey bees. PloS one 6, e26796.

Jeong, C.B., Kim, H.S., Kang, H.M., Lee, J.S., 2017. ATP-binding cassette (ABC) proteins in aquatic invertebrates: Evolutionary significance and application in marine ecotoxicology. Aquatic Toxicol. 185, 29-39.

Kataria, S.K., Chhillar, A.K., Kumar, A., Tomar, M., Malik, V., 2016. Cytogenetic and hematological alterations induced by acute oral exposure of imidacloprid in female mice. Drug and chemical toxicology 39, 59-65.

Kell, D.B. 2015, The transporter-mediated cellular uptake of pharmaceutical drugs is based on their metabolite-likeness and not on their bulk biophysical properties: Towards a systems pharmacology Perspectives in Science 6, 66-83.

Kontreczky, C., Farkas, A., Nemcsok, J., Salanki, J., 1997. Short- and long-term effects of deltamethrin on filtering activity of freshwater mussel (Anodonta cygnea L.). Ecotoxicol. Env. Safety 38, 195-199.

Kudelska, M.M., Holden-Dye, L., O'Connor, V., Doyle, D.A., 2017. Concentration-dependent effects of acute and chronic neonicotinoid exposure on the behaviour and development of the nematode Caenorhabditis elegans. Pest Manag. Sci. 73, 1345-1351.

Kurth, D., Lips, S., Massei, R., Krauss, M., Luckenbach, T., Schulze, T., Brack, W., 2017. The impact of chemosensitisation on bioaccumulation and sediment toxicity. Chemosphere 186, 652-659.

Litman, T., Druley, T.E., Stein, W.D., Bates, S.E., 2001. From MDR to MXR: new understanding of multidrug resistance systems, their properties and clinical significance. Cell. Mol. Life Sci. 58, 931-959. 
Luckenbach, T., Epel, D., 2008. ABCB- and ABCC-type transporters confer multixenobiotic resistance and form an environment-tissue barrier in bivalve gills. Am. J. Physiol. Regul. Integr. Comp. Physiol. 294, R1919-1929.

Marques, C.R., Goncalves, A.M., Pereira, R., Goncalves, F., 2012. Ecotoxicological effects of Mikado and Viper on algae and daphnids. Environ. Toxicol. 27, 685-699.

Morrissey, C.A., Mineau, P., Devries, J.H., Sanchez-Bayo, F., Liess, M., Cavallaro, M.C., Liber, K., 2015. Neonicotinoid contamination of global surface waters and associated risk to aquatic invertebrates: a review. Environ. Int. 74, 291-303.

Mörtl, M., Kereki, O., Darvas, B., Klátyik, S., Vehovszky, A., Győri, J., Székács, A., 2016. Study on Soil Mobility of Two Neonicotinoid Insecticides. J Chem-Ny. Vol. 2016, ID 4546584, http://dx.doi.org/10.1155/2016/4546584

MSDS Canada, Safety Data Sheet CALYPSO ${ }^{8} 480$ SC INSECTICIDE, SDS Number: 102000008338. https://www.cropscience.bayer.ca/ /media/Bayer\%20CropScience/Country-CanadaInternet/Products/Calypso/Calypso\%20480\%20SC\%20Insecticide\%2003-10-14.ashx

Natunen, K., Seppala, J., Schwenk, D., Rischer, H., Spilling, K., Tamminen, T., 2015. Nile Red staining of phytoplankton neutral lipids: species-specific fluorescence kinetics in various solvents. J. Appl. Phycol. 27, 1161-1168.

Navarro, A., Faria, M., Barata, C., Pina, B., 2011. Transcriptional response of stress genes to metal exposure in zebra mussel larvae and adults. Environ. Poll. 159, 100-107.

Navarro, A., Weissbach, S., Faria, M., Barata, C., Pina, B., Luckenbach, T., 2012. Abcb and Abcc transporter homologs are expressed and active in larvae and adults of zebra mussel and induced by chemical stress. Aquat. Toxicol. 122-123, $144-152$.

Neves, M., Castro, B.B., Vidal, T., Vieira, R., Marques, J.C., Coutinho, J.A.P., Goncalves, F., Goncalves, A.M.M., 2015. Biochemical and populational responses of an aquatic bioindicator species, Daphnia longispina, to a commercial formulation of a herbicide (Primextra (R) Gold TZ) and its active ingredient (S-metolachlor). Ecol. Indic. 53, 220-230.

Nwozo, S., Akpodono, E., Oyinloye, B., 2015. Plasma, erythrocyte membrane bound enzymes and tissue histopathology in male Wistar rats exposed to common insecticides. J. Pestic. Sci. 40, 13-18.

Nyman, A.M., Schirmer, K., Ashauer, R., 2014. Importance of toxicokinetics for interspecies variation in sensitivity to chemicals. Environ. Sci. Technol. 48, 5946-5954.

Pain, S., Parant, M., 2003. Response of multixenobiotic defence mechanism in Dreissena polymorpha exposed to environmental stress. Chemosphere 52, 1105-1113.

Pain, S., Parant, M., 2007. Identification of multixenobiotic defence mechanism (MXR) background activities in the freshwater bivalve Dreissena polymorpha as reference values for its use as biomarker in contaminated ecosystems. Chemosphere 67, 1258-1263.

Potet, M., Devin, S., Pain-Devin, S., Rousselle, P., Giamberini, L., 2016. Integrated multi-biomarker responses in two dreissenid species following metal and thermal cross-stress. Environ. Pollut. 218, 39-49.

Rico, A., Van den Brink, P.J., 2015. Evaluating aquatic invertebrate vulnerability to insecticides based on intrinsic sensitivity, biological traits, and toxic mode of action. Environ. Toxicol. Chem. 34, 1907-1917.

Rioult, D., Pasquier, J., Boulange-Lecomte, C., Poret, A., Abbas, I., Marin, M., Minier, C., Le Foll, F., 2014. The multixenobiotic resistance (MXR) efflux activity in hemocytes of Mytilus edulis is mediated by an ATP binding cassette transporter of class C (ABCC) principally inducible in eosinophilic granulocytes. Aquat. Toxicol. 153, 98-109.

Rittschof, D., McClellan-Green, P., 2005. Molluscs as multidisciplinary models in environment toxicology. Marine Poll. Bull. 50, 369-373.

Salanki, J., Farkas, A., Kamardina, T., Rozsa, K.S., 2003. Molluses in biological monitoring of water quality. Toxicol. Lett. 140-141, 403-410.

Schaafsma, A., Limay-Rios, V., Xue, Y., Smith, J., Baute, T., 2016. Field-scale examination of neonicotinoid insecticide persistence in soil as a result of seed treatment use in commercial maize (corn) fields in southwestern Ontario. Environ. Toxicol. Chem. 35, 295-302. a szövegben 2015?

Sgolastra, F., Medrzycki, P., Bortolotti, L., Renzi, M.T., Tosi, S., Bogo, G., Teper, D., Porrini, C., Molowny-Horas, R., Bosch, J., 2017. Synergistic mortality between a neonicotinoid insecticide and an ergosterol-biosynthesis-inhibiting fungicide in three bee species. Pest Manag. Sci. 73, 1236-1243. 
Sheets, L.P., Li, A.A., Minnema, D.J., Collier, R.H., Creek, M.R., Peffer, R.C., 2016. A critical review of neonicotinoid insecticides for developmental neurotoxicity. Crit. Rev. Toxicol. 46, 153-190.

Simon-Delso, N., Amaral-Rogers, V., Belzunces, L.P., Bonmatin, J.M., Chagnon, M., Downs, C., Furlan, L., Gibbons, D.W., Giorio, C., Girolami, V., Goulson, D., Kreutzweiser, D.P., Krupke, C.H., Liess, M., Long, E., McField, M., Mineau, P., Mitchell, E.A., Morrissey, C.A., Noome, D.A., Pisa, L., Settele, J., Stark, J.D., Tapparo, A., Van Dyck, H., Van Praagh, J., Van der Sluijs, J.P., Whitehorn, P.R., Wiemers, M., 2015. Systemic insecticides (neonicotinoids and fipronil): trends, uses, mode of action and metabolites. Environ. Sci. Pollut. Res. 22, 5-34.

Smital, T., Kurelec, B., 1997. Inhibitors of the multixenobiotic resistance mechanism in natural waters: In vivo demonstration of their effects. Environ. Toxicol. Chem. 16, 2164-2170.

Smital, T., Kurelec, B., 1998. The chemosensitizers of multixenobiotic resistance mechanism in aquatic invertebrates: a new class of pollutants. Mutat. Res. 399, 43-53.

Smital, T., Luckenbach, T., Sauerborn, R., Hamdoun, A.M., Vega, R.L., Epel, D., 2004. Emerging contaminants-pesticides, PPCPs, microbial degradation products and natural substances as inhibitors of multixenobiotic defense in aquatic organisms. Mutat. Res. 552, 101-117.

Smital, T., Sauerborn, R., Hackenberger, B.K., 2003. Inducibility of the P-glycoprotein transport activity in the marine mussel Mytilus galloprovincialis and the freshwater mussel Dreissena polymorpha. Aquatic Toxicol. 65, 443-465.

Smital, T., Sauerborn, R., Pivcevic, B., Krca, S., Kurelec, B., 2000. Interspecies differences in P-glycoprotein mediated activity of multixenobiotic resistance mechanism in several marine and freshwater invertebrates. Comp. Biochem. Physiol. C Toxicol. Pharmacol. 126, 175-186.

Tavares, D.A., Dussaubat, C., Kretzschmar, A., Carvalho, S.M., Silva-Zacarin, E.C.M., Malaspina, O., Berail, G., Brunet, J.L., Belzunces, L.P., 2017. Exposure of larvae to thiamethoxam affects the survival and physiology of the honey bee at post-embryonic stages. Environ. Poll. 229, 386-393.

Terayama, H., Endo, H., Tsukamoto, H., Matsumoto, K., Umezu, M., Kanazawa, T., Ito, M., Sato, T., Naito, M., Kawakami, S., Fujino, Y., Tatemichi, M., Sakabe, K., 2016. Acetamiprid Accumulates in Different Amounts in Murine Brain Regions. Int. J. Environ. Res. Publ. Health 13.

Tomizawa, M., Casida, J.E., 2005. Neonicotinoid insecticide toxicology: mechanisms of selective action. Ann. Rev. Pharmacol. Toxicol. 45, 247-268.

Tutundjian, R., Minier, C., 2007. Effect of temperature on the expression of P-glycoprotein in the zebra mussel, Dreissena polymorpha. J. Therm. Biol. 32, 171-177.

Vehovszky, A., Farkas, A., Acs, A., Stoliar, O., Szekacs, A., Mortl, M., Gyori, J., 2015. Neonicotinoid insecticides inhibit cholinergic neurotransmission in a molluscan (Lymnaea stagnalis) nervous system. Aquat. Toxicol. 167, 172-179

Wathsala, R.H.G.R., Franzellitti, S., Scaglione, M., Fabbri, E., 2018. Styrene impairs normal embryo development in the Mediterranean mussel (Mytilus galloprovincialis). Aquat. Toxicol. 201, 58-65. 


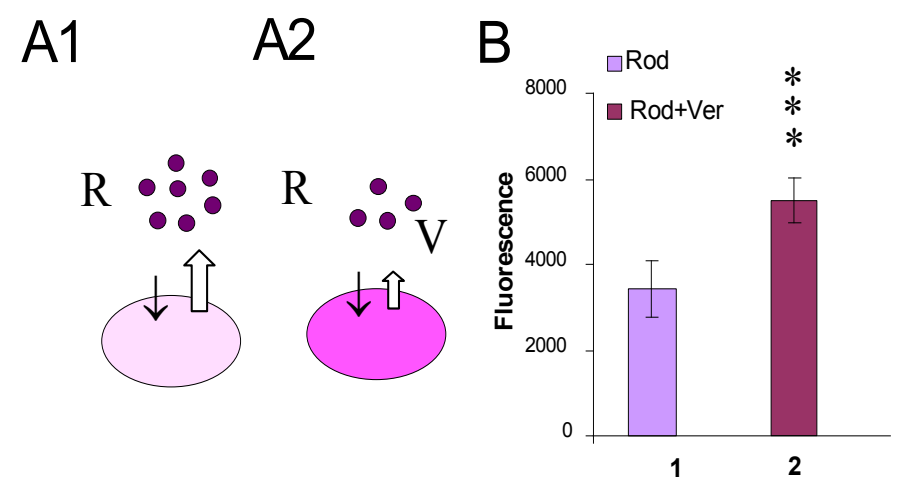

Fig. 1. Experimental setup for MXR assay A. In rhodamine B (R) solution the fluorescent dye is accumulating intracellularly by gradient-controlled uptake $(\downarrow)$, while MXR provides an efflux (介) to remove rhodamine against the concentration gradient (A1). Verapamil (V) inhibits the MXR, resulting in enhanced accumulation of rhodamine (A2). B. Fluorescence data show that rhodamine accumulation (Rod) is increased in gills simultaneously co-incubated in verapamil (Rod+Ver). Data (on $\mathrm{y}$ axis) are expressed as fluorescence unit per $\mathrm{mg}$ tissue protein. $*^{* *}(p<0.001)$ denote significant differences in rhodamine content of samples (Student's $t$-test). ( $\mathrm{n}=6$, mean $\pm \mathrm{SD}$ ). 

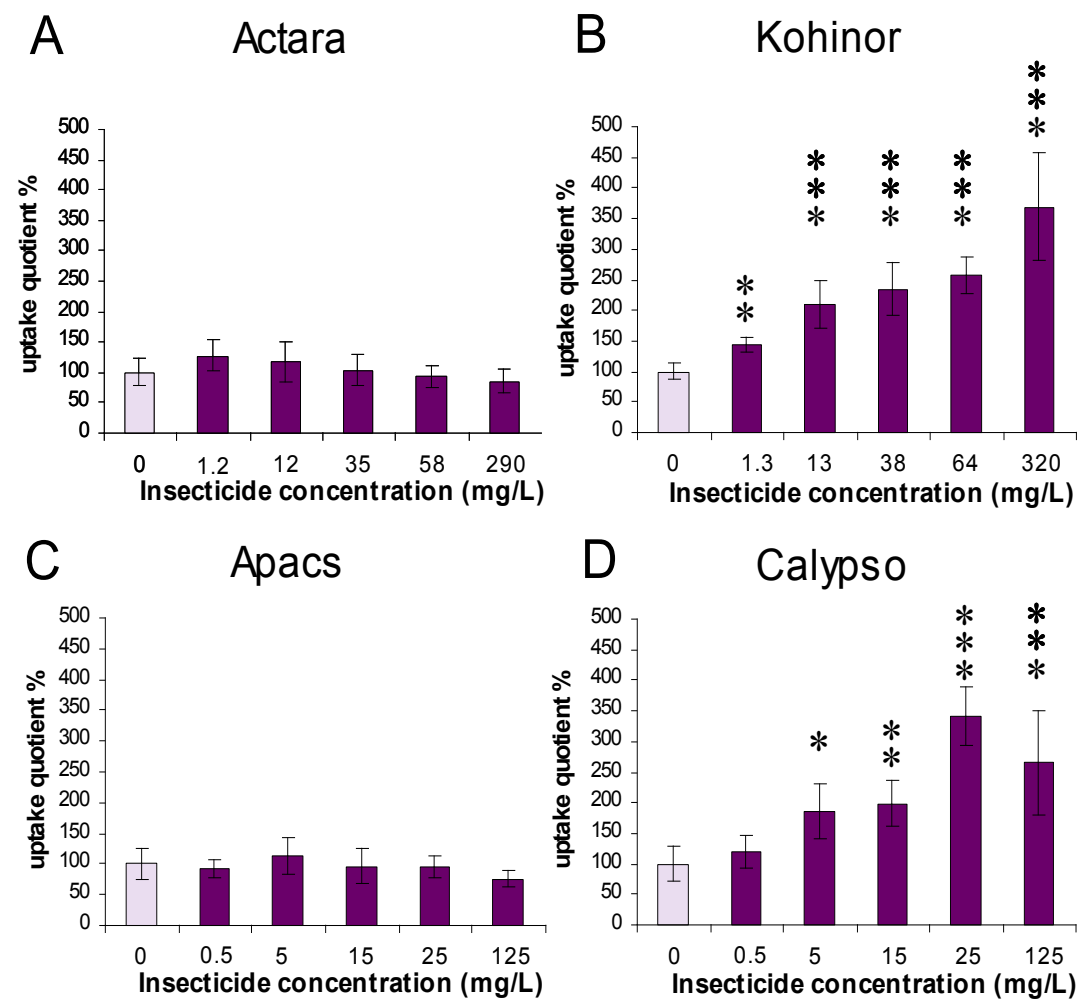

Fig. 2. Effects of equimolar, graded concentrations of neonicotinoid insecticides on rhodamine accumulation in isolated gills. The uptake quotients (\%) do not show significant changes in samples incubated in Actara (A) and Apacs (C) but the gills incubated in Kohinor (B) and Calypso (D) show significant increase. Note the same concentration ranges (formulated products, $\mathrm{mg} / \mathrm{L}$ ) of Apacs and Calypso (A, B) and also Actara and Kohinor (C, D), respectively. The significance of treatments on rhodamine uptake versus control was assessed by ANOVA followed by Tukey's post hoc test with Bonferroni correction $(* p<0.05 ; * * p<0.01 ; * * * p<0.001$ ). 


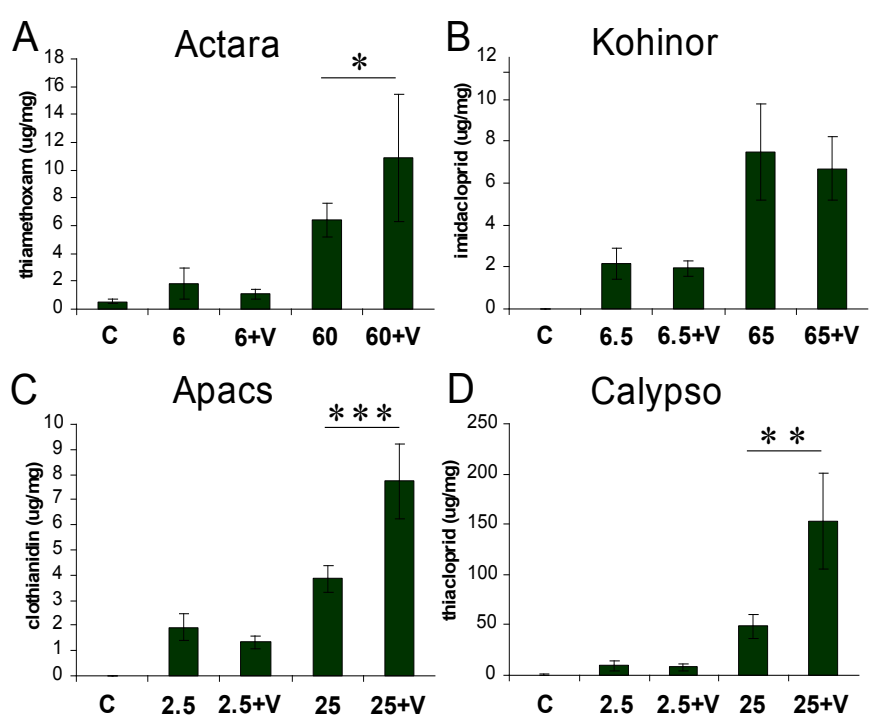

Fig. 3. Analytical measurements show accumulation of thiamethoxam (A), imidacloprid (B) clothianidin (C) and thiacloprid (D) in isolated gill tissues incubated in Actara, Kohinor, Apacs and Calypso, respectively. Incubation concentrations are expressed as $\mathrm{mg} / \mathrm{L}$ of the formulated product, corresponding with equimolar concentrations of its active neonicotinoid component (e.g. 6mg/L and $60 \mathrm{mg} / \mathrm{L}$ concentrations of Actara correspond with $5 \mu \mathrm{M}$ and $50 \mu \mathrm{M}$ thiamethoxam content). Higher levels of neonicotinoids in samples co-incubated with verapamil $(+\mathrm{V})$ are significant in $\mathrm{A}, \mathrm{C}$ and $\mathrm{D}$. Values on $\mathrm{Y}$ axis show the measured neonicotinoid concentrations (active ingredients) expressed as $\mu \mathrm{g}$ neonicotinoid per $\mathrm{mg}$ tissue. $*(p<0.05), * *(p<0.01)$ and $* * *(p<0.001)$ indicate significance levels between samples (Student's $t$-test). 


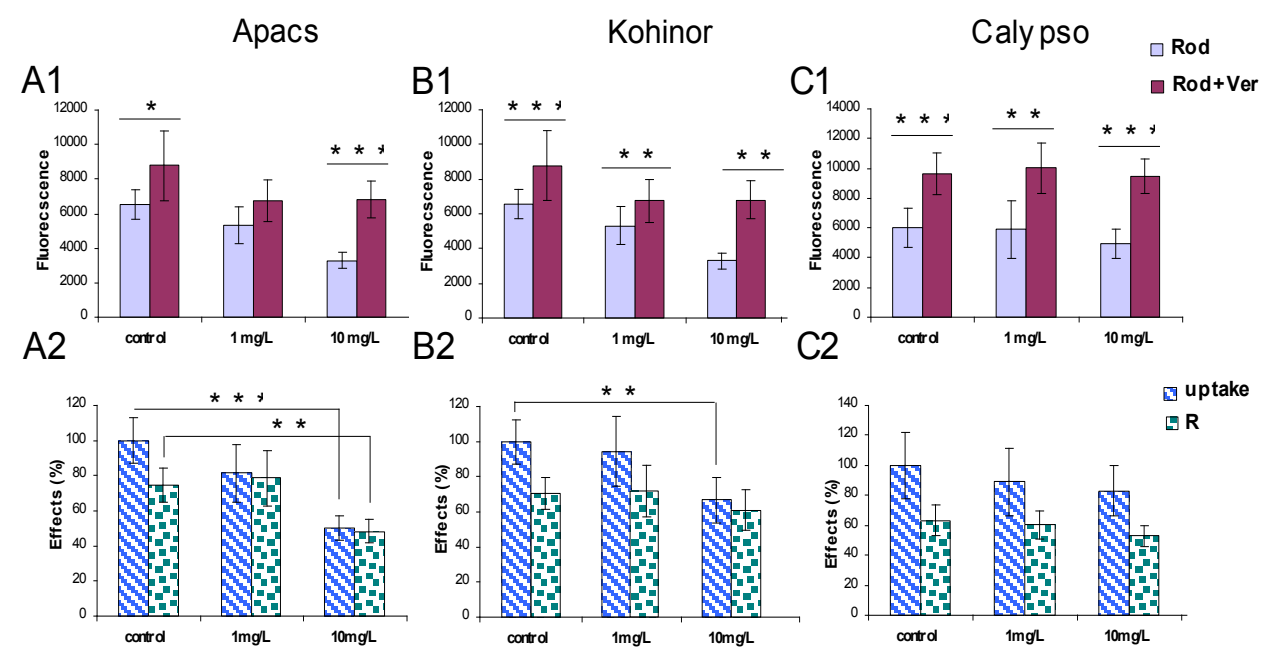

Fig. 4. Fluorescence data of sample experiments with Apacs (A1) and Kohinor (B1) and Calypso (C1) on the $14^{\text {th }}$ day of exposure show decreased rhodamine concentrations in gill tissues $(1 \mathrm{mg} / \mathrm{L}$, $10 \mathrm{mg} / \mathrm{L}$ treatment $)$ compared with control group; * $(p<0.05), * *(p<0,01)$ and $* * *(p<0.001)$ indicate significant differences in rhodamine accumulation (Student's $t$-test). The uptake quotients are significantly lower in samples treated with $10 \mathrm{mg} / \mathrm{L}$ Apacs (A2) and 10mg/L Kohinor (B2) but only $10 \mathrm{mg} / \mathrm{L}$ Apacs resulted significant decrease of verapamil inhibition (lower $\mathrm{R}$ value, A2), (ANOVA, Tukey's post hoc test $(* p<0.05 ; * * p<0.01 ; * * * p<0.001)$ ). 

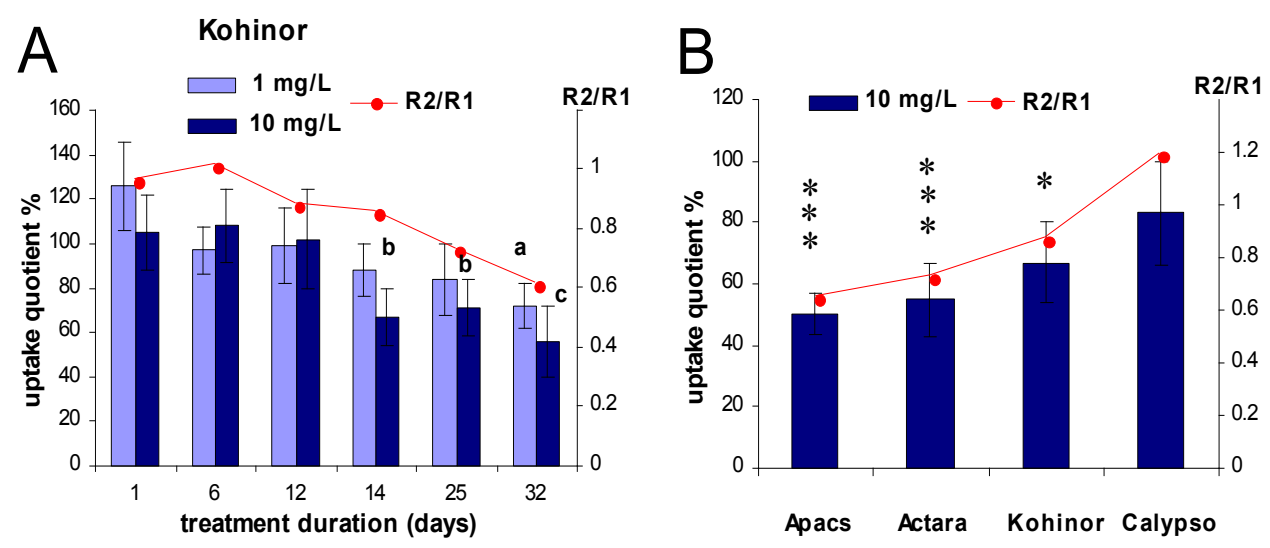

Fig. 5. A. Time- and dose-dependent decrease of rhodamine accumulation expressed in uptake quotients (calculated as percentages of control) demonstrates gradually decreasing rhodamine accumulation during the $(1,10 \mathrm{mg} / \mathrm{L})$ Kohinor treatment (ANOVA, Tukey's post hoc test: a $(p<$ $0.01)$; b $(p<0.05)$; $\mathrm{c}(p<0.01))$. Decreasing values of $\mathrm{R} 2 / \mathrm{R} 1$ ratio (on right axis) compares verapamil inhibition of $10 \mathrm{mg} / \mathrm{L}$ treatment (R2) and control (R1). B. Summarized data compare the same $\left(14^{\text {th }}\right)$ day uptake quotients (relative to control, as 100 percent), showing the greatest effect, significant decrease of uptake compared to control by in Actara and Apacs treatments. Values on the right axis (R2/R1) similarly suggest the most enhanced MXR activity in Actara, Apacs and Kohinor but not in Calypso (ANOVA, Tukey's post hoc test: * $(p<0.05) ; * *(p<0.01))$. 